\title{
MEGAESÔFAGO SECUNDÁRIO A PERSISTÊNCIA DO ARCO AÓRTICO DIREITO EM CÃO DA RAÇA PASTOR ALEMÃO - RELATO DE CASO
}

\author{
(Megaesophagus secondary to persistence of the right aortic arch in a German shepherd dog - case report)
}

1Júlia Meira, ${ }^{2}$ Cinthia Garcia, ${ }^{3}$ sadora Scherer Borges, ${ }^{4}$ Lucas Dornelles dos Reis, ${ }^{5}$ Wesley Renosto Lopes

\begin{abstract}
${ }^{1}$ Médica Veterinária Autônoma, Florianópolis, Santa Catarina, Brasil. ${ }^{2}$ Hospital Veterinário Renata Saccaro, Caxias do Sul, Rio Grande do Sul, Brasil. ${ }^{3}$ Médica Veterinária Autônoma, Palmeira das Missões, Rio Grande do Sul, Brasil. ${ }^{4}$ Universidade de Caxias do Sul, Caxias do Sul, Rio Grande do Sul, Brasil. ${ }^{5}$ Clínica Ducão Veterinária, Caxias do Sul, Rio Grande do Sul, Brasil.
\end{abstract}

*Correspondência: meirajuli@gmail.com

RESUMO: O megaesôfago é um transtorno relacionado a dilatação e hipomotilidade esofágica e é considerado a principal causa de regurgitação em cães. Pode ocorrer de forma primária ou secundária, classificado em congênito, adquirido idiopático e adquirido secundário. A forma secundária adquirida pode ocorrer em inúmeras circunstâncias, e dentre elas evidencia-se as anomalias de anel vascular, como a persistência do arco aórtico direito (KOZU et al., 2015). Estas anomalias são malformações congênitas dos principais vasos da base do coração, os quais, por estarem em posições errôneas, comprimem o esôfago ou a traqueia, acarretando obstrução física desses órgãos e ocasionando afecções digestivas ou respiratórias (MENZEL; DISTL, 2011). O objetivo deste resumo é descrever o caso de um cão, macho, com quatro meses de idade que foi atendido na Clínica Ducão Veterinária, Caxias do Sul/RS, pesando $8,6 \mathrm{~kg}$, da raça Pastor Alemão com histórico de êmese recorrente. Ao exame físico do paciente foi observado baixo escore corporal, 5 em uma escala de 0-10, retardo no crescimento e desidratação de $3 \%$. Mucosas apresentavam-se normocoradas, tempo de perfusão capilar de dois segundos, linfonodos não reativos, frequência cardíaca, frequência respiratória e temperatura retal dentro dos parâmetros fisiológicos da espécie. Foi solicitado hemograma e exame radiográfico simples e contrastado de região cérvico-torácica. No exame hematológico constatou-se em aumento nos valores de eritrócitos, hematócrito, hemoglobina e diminuição de proteínas totais caracterizando assim, uma policitemia relativa devido ao estado de desidratação e hipoproteinemia por desnutrição. No exame radiográfico simples foi observado lúmen traqueal deslocado cranialmente em sua porção torácica e perda da conformação normal da silhueta cardíaca, sugerindo anomalia por aneladura vascular e na radiografia contrastada, observou-se esôfago dilatado cranialmente a base do coração, levando ao diagnóstico de megaesofâgo. Desta forma, foi indicado oferecer alimentação pastosa de forma elevada, aproximadamente $45 \mathrm{~cm}$ do chão. $O$ tratamento clínico é realizado, mas o procedimento cirúrgico é preconizado por haver uma melhora significativa dos sinais clínicos (MENZEL; DISTL, 2011). O paciente aqui relatado demonstrou melhoras após a mudança no manejo alimentar, porém não de forma satisfatória, sendo encaminhado precocemente para a correção cirúrgica através da secção do ducto arterioso, garantindo um prognóstico satisfatório.

Palavras-chave: aneladura vascular; radiografia contrastada; regurgitação

\section{Referências}

KOZU, F.O; SILVA, R.D; SANTOS, M.C.F.P. Doenças do Trato Digestório: Doenças do esôfago. 2 In: Jérico, M.M; Andrade, J.P; Kogika, M.M. Tratado de Medicina Interna de cães e gatos, $1^{\circ}$ edição, Rio de Janeiro, Roca, 2015. p. 2933-2941.

MENZEL, J.; DISTL, O. Unusual vascular ring anomaly associated with a persistent right aortic arch and an aberrant left subclavian artery in German pinschers. Veterinary Journal, v. 187, n. 3, p. 352 - $355-2011$. 